\title{
Effect of impact energy on wear behavior of high chromium white iron produced by liquid die forging
}

\author{
B Qiu ${ }^{1}$, S M Xing ${ }^{1, a}$, Q Dong ${ }^{1}$, H Liu ${ }^{2}$ \\ ${ }^{1}$ School of Mechanical, Electronic and Control Engineering, Beijing Jiaotong University, China \\ ${ }^{2}$ School of Economics and Management, Beijing Jiaotong University, China
}

\begin{abstract}
Impact abrasive wear behavior of high chromium white iron (HCWI) produced by liquid die forging process were investigated. the wear tests were performed with the MLD-10 abrasive wear testing machine, using $\mathrm{SiO}_{2}$ abrasive and with four impact energies of $1.5 \mathrm{~J}, 2.5 \mathrm{~J}, 3.5 \mathrm{~J}$ and $4.5 \mathrm{~J}$ for $120 \mathrm{~min}$. The results indicated that the cumulative volume loss of HCWI sample increases with the growth of impact energy, and exhibits best wear resistance under low impact condition. For given impact energy, the volume loss increases with the increasing of wear time, which shown an approximately liner tendency. The macro-morphologies, SEM images of worn surface and cross-sectional images of wear samples were observed by optical microscope and SEM, and the wear mechanism and characteristics were analyzed. Results shown that the wear characteristics is mainly based on the shallow ploughing and accompanied by plastic deformation under lower impact energy, while the fatigue peeling and embedded abrasive become the most significant characteristics when the impact energy is higher.
\end{abstract}

\section{Introduction}

As one of the three failure forms of materials in engineering (the others are fatigue and corrosion), wear leads to both significant economic and environmental losses due to shortening the working life of equipment $[1,2]$. Typical wear can be divided into five categories as: abrasive, adhesive, erosive, fretting and chemical wear [3]. Among them, abrasive wear mainly exists in the transportation, mining and mineral processing industries, and accounts for roughly about $50 \%$ of industrial wear situations [4,5]. In general, abrasive wear is the process by which the surfaces of components are damaged by the gouging and scratching action of hard abrasives trapped between the contacting surfaces during the wear.

Impact abrasive wear, as one of the forms of abrasive wear, prominently increases the mass loss of materials as it combines friction and impact [6], has been gradually reported in recent years. Latest researches, however, start focus on advanced wear service materials such as metal matrix composites, coating, and cemented carbide [7-9]. But it is well-known that iron and steel material cannot be replaced in engineering, such as high chromium white iron (HCWI), has widely used in several structural applications as the third-generation wear-resistant materials, which attributed to the multiple advantages of HCWI such as high strength and wear resistance [10]. Little attention has been paid to the effect of impact energy on the wear mechanism and characteristics for the traditional HCWI material under impact wear condition. It would be of great importance to study the wear

\footnotetext{
${ }^{\mathrm{a}}$ Corresponding author: smxing@bjtu.edu.cn
}

properties of HCWI as the composite components are often subject to wear loading conditions in service in various industries. In this paper, HCWI were prepared by liquid die forging process with conventional melting and casting route. The impact wear resistance of HCWI was investigated under casting conditions. The present work highlights the influence of impact energy on the wear characteristic and the wear mechanism of HCWI

\section{Materials and experimental procedures}

The high chromium white iron (HCWI) used in the present study were melted in a $25 \mathrm{~kg}$ laboratory intermediate frequency induction furnace by using highpurity raw materials. Then the melt was rapidly superheated to $1560-1580{ }^{\circ} \mathrm{C}$. After holding at the temperature for $5 \mathrm{~min}$, the molten alloy was poured into the squeeze casting die placed on the bed of a 200 tones hydraulic press and was immediately squeezed at 115 MPa pressure. The die was made of heat treated H13 steel and was preheated to about $200{ }^{\circ} \mathrm{C}$ before casting. The chemical composition of $\mathrm{HCWI}$ is $26 \% \mathrm{Cr}, 2.8 \% \mathrm{C}$, $1.8 \% \mathrm{Mn}, 0.8 \% \mathrm{Si}, 0.8 \% \mathrm{Mo}, 0.4 \% \mathrm{Ni}$ and balance $\mathrm{Fe}$ (all in wt.\%).

Samples for metallography, impact and wear tests were cut from the cast bars, respectively. The metallographic samples $(8 \mathrm{~mm} \times 8 \mathrm{~mm} \times 10 \mathrm{~mm})$ were cut with metallographic cutting machine and prepared according to standard mechanical polishing techniques, followed by etching with four percent Nital solution $(4 \mathrm{ml}$ 
$\mathrm{HNO}_{3}+98 \mathrm{ml}$ ethanol) to reveal the microstructure. Optical microscope (OM, DM2000X, Leica) was used to observe the microstructure of samples. The hardness of HCWI is tested by a Rockwell hardness tester (TH300) with the load of $150 \mathrm{kgf}$ and the holding time of $2 \mathrm{~s}$. Ten readings are measured and take an average as the final result. The non-notched impact test samples $(10 \mathrm{~mm} \times 10 \mathrm{~mm} \times 55 \mathrm{~mm})$ were prepared to measure the impact toughness of HCWI, and the test was performed on a JB-50 impact tester made in China. Three impact samples were tested for different composites, then take the average value as the result. The fracture surface of the impact samples was observed by scanning electron microscopy (SEM, EVO18, Carl Zeiss) equipped with an energy dispersive spectrometer (EDS).

The wear tests were performed on a dynamically loaded abrasive wear tester (MLD-10, produced by Zhangjiakou Cheng Xin Testing Equipment Manufacturing Co. Ltd., China) at room temperature, the schematic representation was exhibited in Figure 1 (a), the impact-abrasion wear of the samples is realized with the non-stop rotating of the lower sample and the vertical reciprocating motion of the upper sample. The experimental material (upper sample) were cut into 10 $\mathrm{mm} \times 10 \mathrm{~mm} \times 30 \mathrm{~mm}$ size, as shown in Figure 1 (a), and the surface of $10 \mathrm{~mm} \times 10 \mathrm{~mm}$ was mechanically polished for impact-abrasive wear tests. The counterpart ring (lower sample) was made of $45 \#$ steel (58HRC) with the size of $50 \mathrm{~mm}$ in diameter and $20 \mathrm{~mm}$ in length, which was quenched at $840^{\circ} \mathrm{C}$ in water and tempered at $300^{\circ} \mathrm{C}$ for $1 \mathrm{~h}$. During the test, the wear sample is fixed on a clamping chuck which connects with a hammer. The impact frequency of wear sample was 150 times $/ \mathrm{min}$, the rotation speed of contract sample was $200 \mathrm{r} / \mathrm{min}$, and the impact energy is set at $2 \mathrm{~J}, 3 \mathrm{~J}$ and $4 \mathrm{~J}$, respectively. Refined quartz sands are used as the abrasive material (with particle size of 10-20 mesh, density of $2.6 \mathrm{~g} / \mathrm{cm}^{3}$ and hardness value of $800 \mathrm{HV}-1200 \mathrm{HV}$ ). The process of the wear test was shown in Figure 1 (b). Each sample was subjected to pre-wear for $30 \mathrm{~min}$ before the formal tests. The wear mass loss was measured every 10 minutes in the tests, before and after each test, the wear sample was cleaned ultrasonically, dried and then weighed by a precision electronic balance with an accuracy of $0.0001 \mathrm{~g}$, and take the average value of three measurements as the results. The wear tests were performed for 120 minutes, and the wear tests were repeated three times with new samples for each test condition to ensure the reliability. The wear surfaces of the tested samples were observed and examined by SEM.

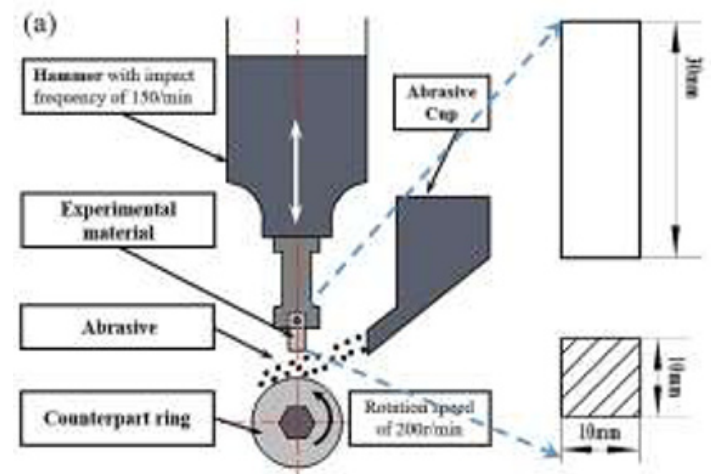

(b)

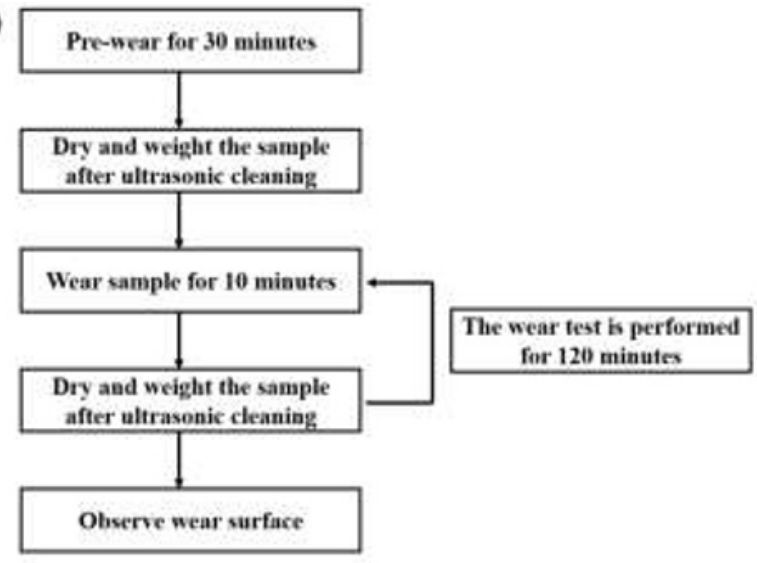

Figure 1. (a) The schematic of wear tester and the size of wear sample; (b) The flow chart of impact wear test.

\section{Results and discussion}

\subsection{Microstructure and impact property of HCWI}

The metallograph of HCWI under low and high times are show in Figure 2, the microstructure of HCWI exhibits a typical dendritic structure, which consists of the martensite and retained austenite in the form of off-white dendrites, as well as the eutectic structure between dendrites (Figure 2 (a)). The eutectic between dendrites are composed of alloy carbide, martensite and retained austenite, and the carbide, which shaped fish-bone, stripy or massive, distributed in the martensite and small amount of retained austenite matrix (Figure 2 (b)). The hardness test results show that the average macrohardness of HCWI reaches to $48.86 \mathrm{HRC}$, and the impact test shows that the impact toughness of HCWI reaches to $9.43 \mathrm{~J} \cdot \mathrm{cm}^{-2}$. The SEM micrograph of fractured surface of the HCWI is shown in Figure 3 (a). It can be seen that the fracture characteristics is river pattern, which formed by the confluence of cleavage steps. The fracture morphology indicates the fracture mechanism is dominated by cleavage fracture, which consistent with the fracture characteristics of HCWI. In addition, the energy spectrum analysis results of the regions 1 is shown in Figure 3 (b), It can be observed that the main elements of the region 1 are $\mathrm{Fe}$ and $\mathrm{Cr}$.

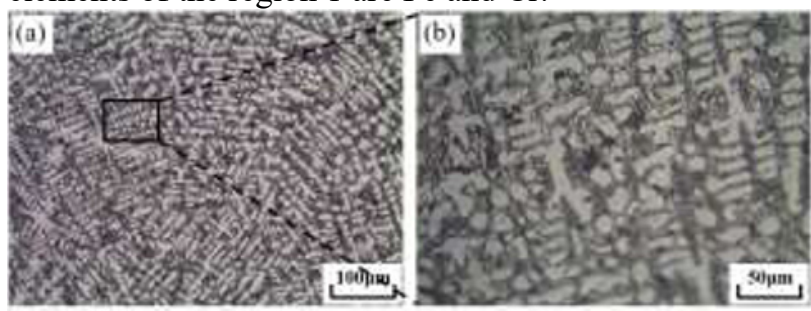

Figure 2. The microstructure of HCWI under (a) low and (b) high magnification 

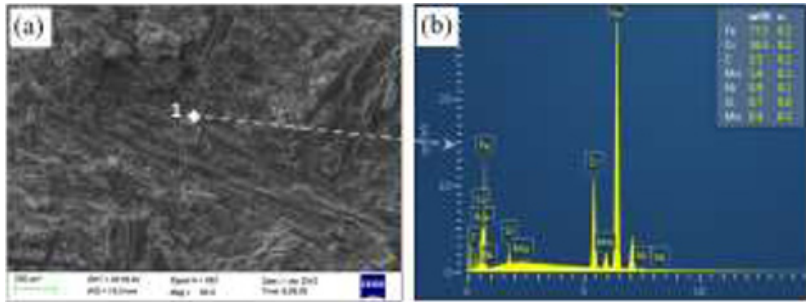

Figure 3. (a) The typical micrograph of fracture surface of HCWI (b) EDS analysis

\subsection{Analysis of volume loss of wear samples}

The volume loss of HCWI samples as a function of wear time under different impact energies is given in Figure 4 (a). For given impact energy, the volume loss increases with the increasing of wear time, which shown an approximately liner tendency. And the fitting curve equation between volume loss and wear time is $y=0.0015 x-0.02175, y=0.00154 x-0.01436$ $y=0.00155 x-0.078$ and $y=0.00158 x+0.00186$ for $1.5 \mathrm{~J}, 2.5 \mathrm{~J}, 3.5 \mathrm{~J}$ and $4.5 \mathrm{~J}$, respectively. Meanwhile, the confidence level of the linear fitting is all greater than 0.99. Fig. 4 (b) shows the influence of impact energy on the cumulative volume loss of the HCWI. It can be seen that the cumulative volume loss of tested material increases with the growth of impact energy, which illustrates that the minimum and maximum volume loss occur under the impact energy of $1.5 \mathrm{~J}$ and $4.5 \mathrm{~J}$. Accordingly, the HCWI exhibits best wear resistance under low impact condition.
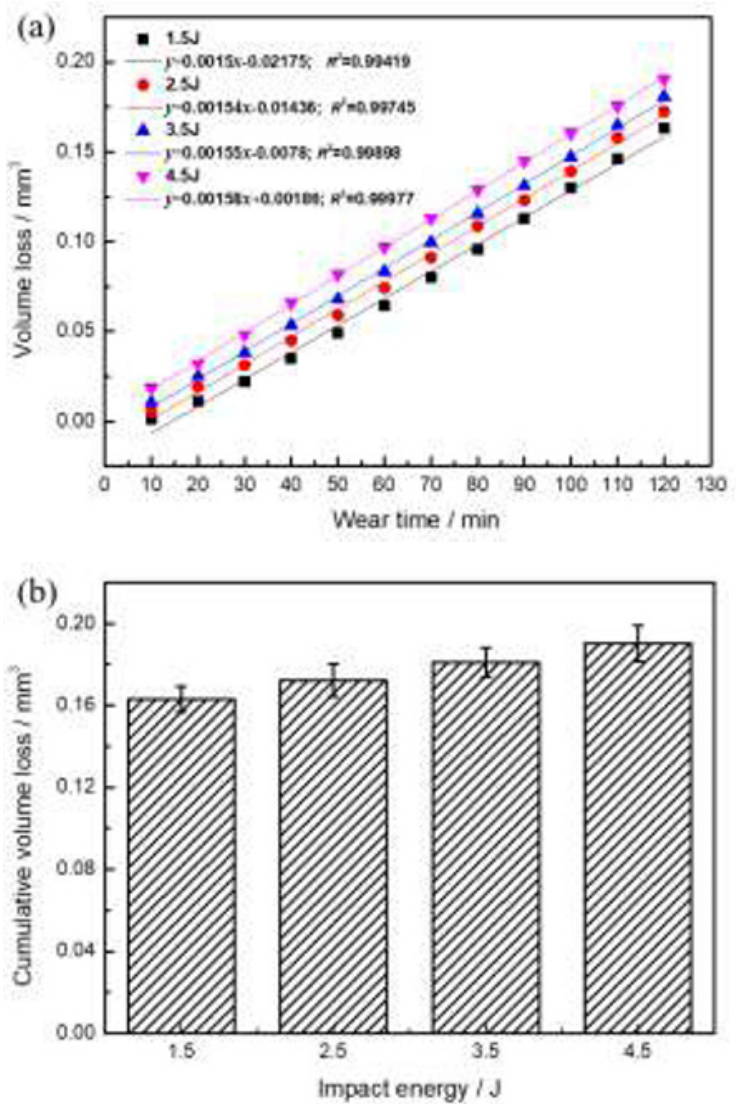

Figure 4. (a) The relationship between volume loss and wear time under different impact energy; (b) Variation of cumulative volume loss with impact energy for HCWI.

\subsection{Analysis of worn surface of wear samples}

In order to get a better understanding of impact-abrasive wear mechanism, as well as the effect of impact energy and wear time on wear behavior, investigation of the worn surface will be necessary. Figure 5 presents the macro-morphologies, SEM images of worn surface and cross-sectional images of the HCWI samples after a wear time of 120 min under the impact energies from $1.5 \mathrm{~J}$ to 4.5 J. It can be seen form the macro-morphologies of worn surface that the wear loss is gradually increasing with the impact energy. Correspondingly, the "wear pit" caused by impact and wear is bigger and deeper with the impact energies, which can be further illustrated from the cross-sectional images of worn surface. The depth of the "wear pit" in worn surface is $1.6 \mathrm{~mm}$ for $1.5 \mathrm{~J}, 1.9 \mathrm{~mm}$ for $2.5 \mathrm{~J}, 2.1 \mathrm{~mm}$ for $3.5 \mathrm{~J}$ and $2.2 \mathrm{~mm}$ for $4.5 \mathrm{~J}$, respectively, as is seen in Figure 5. In addition, it can be observed form the SEM images of samples that the worn surfaces show three kinds of morphological characteristics, such as ploughing-cutting (as indicated by the arrow in Figure 5 (a) and (b)), fatigue peeling (as indicated by the arrow in Figure 5 (d)) and embedded abrasive (as indicated by the arrow in Figure 5 (c) and (d)).

During the impact abrasive wear process, the samples impacted the counterpart ring periodically, as well as the flowing abrasive between them. Under the lower impact energy (i.e. $1.5 \mathrm{~J}$ ), the wear characteristics is mainly based on the shallow ploughing [11]. For the HCWI, the hard phase is $\mathrm{M}_{7} \mathrm{C}_{3}$ carbides, and the soft phase is martensite matrix, when the impact energy is low, the abrasive particles were squeezed into the softer martensite matrix at low contact pressure, the depth of indentation is shallow, and then the ploughing wear occurred on the matrix under the action of tangential stress $[12,13]$, the ploughing is shallow and the wear loss is small. In addition, the plastic deformation is also observed on the worn surface, which caused by the existence of retained austenite in the matrix. When the impact energy increases to a medium value, like $2.5 \mathrm{~J}$ and $3.5 \mathrm{~J}$, it can be seen that the ploughing is wider and deeper, and the cutting trace were clearly seen (Figure 5 (b)). That is because with the increase of impact energy, the acting force that abrasive to matrix is increase, and the depth of the pierce into the matrix increases. The cutting wear of the material is carried out under the action of tangential stress, and the cutting mechanism dominated the wear process. In addition, the embedded abrasive can be observed in worn surface when the impact energy is $3.5 \mathrm{~J}$ (Figure 5 (c)). When the impact energy increases to a high value (i.e. $4.5 \mathrm{~J}$ ), the fatigue peeling and embedded abrasive become the most significant characteristics. Under the high energy, massive carbides were subjected to larger impact force, resulting in local fatigue cracks, then the cracks expand rapidly, and following by the break of carbides and separate from the matrix. Besides that, the embedded abrasive can also be observed under the impact condition of $4.5 \mathrm{~J}$. The embedded abrasive experienced the following steps: firstly, the abrasive with high brittleness was broken under the high impact effect and debris of abrasive occurred; then the sharp debris was squeezed into material under impact condition of the 
hammer and pierced into the material under the slide condition of the ring; next the crack produced by piercing expanded with exceeding the tensile strength limit; finally, the material that pierced into the debris separated from the surface and its debris mixed with abrasive caused further wear.

\subsection{Analysis of morphologies of counterpart ring} In order to study the wear condition of the counterpart rings during the wear tests, the worn morphologies of the rings, which corresponding to the different impact energies were observed, and the obtained images are shown in Figure 6. It can be seen that the wear characteristic of the counterpart ring dominates by the continuous furrows that has occurred plastic deformation (F-PD) under the different impact energies. Since the condition of abrasives under the contact stress, the furrows firstly occurred in the surface of the ring, and further plastic deformation happened in the furrows due to the constant and rotary wear condition, thus formed the obvious and continuous F-PD, and the trace of F-PD can be clearly seen. In addition, the embedded abrasive particle under the high impact energy can also be observed (Figure $6(\mathrm{~d})$ ).

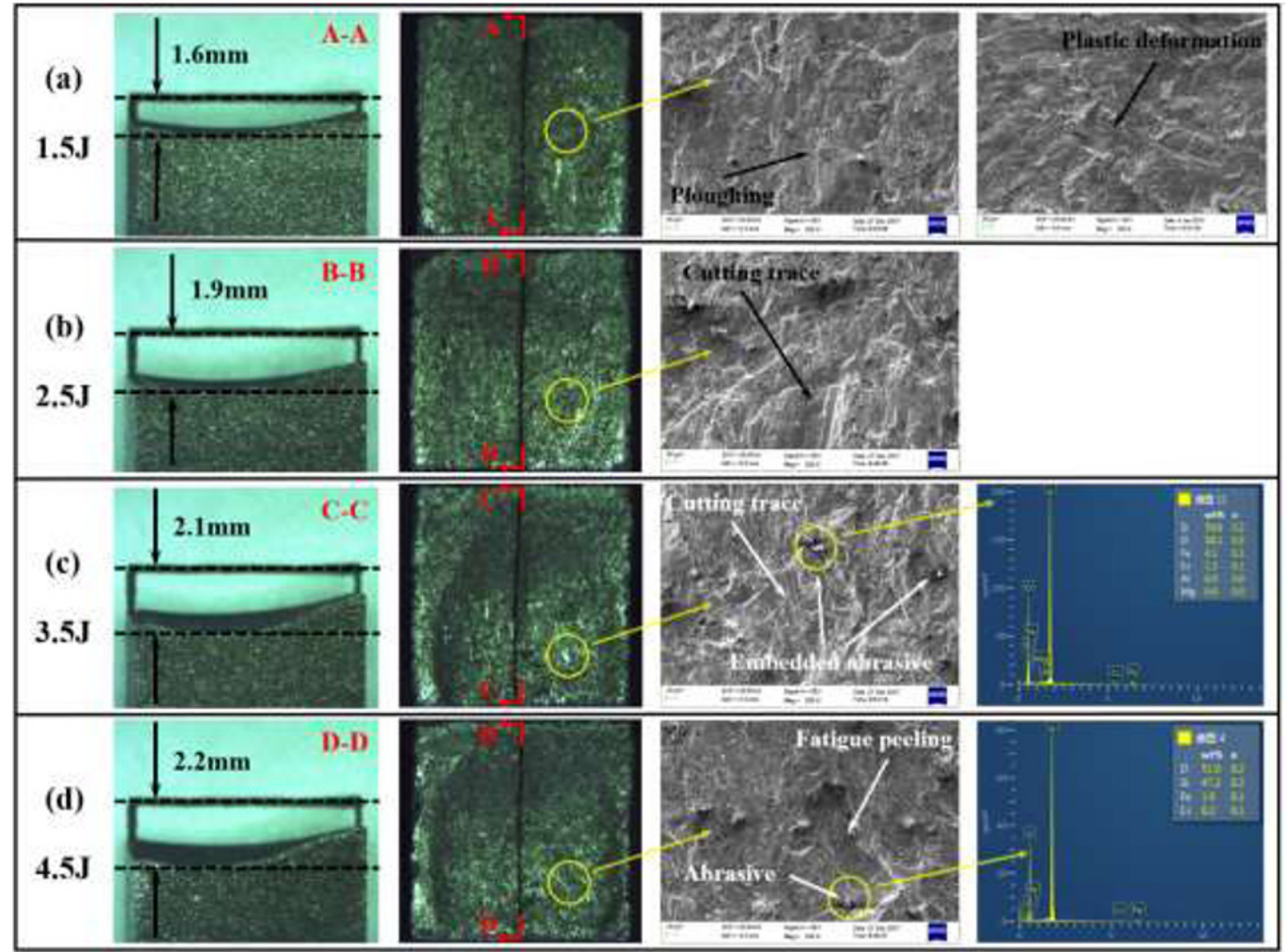

Figure 5. The worn surface and cross-sectional images of the wear samples under different impact energies: (a) $1.5 \mathrm{~J}$; (b) $2.5 \mathrm{~J}$; (c) $3.5 \mathrm{~J}$; (d) $4.5 \mathrm{~J}$.
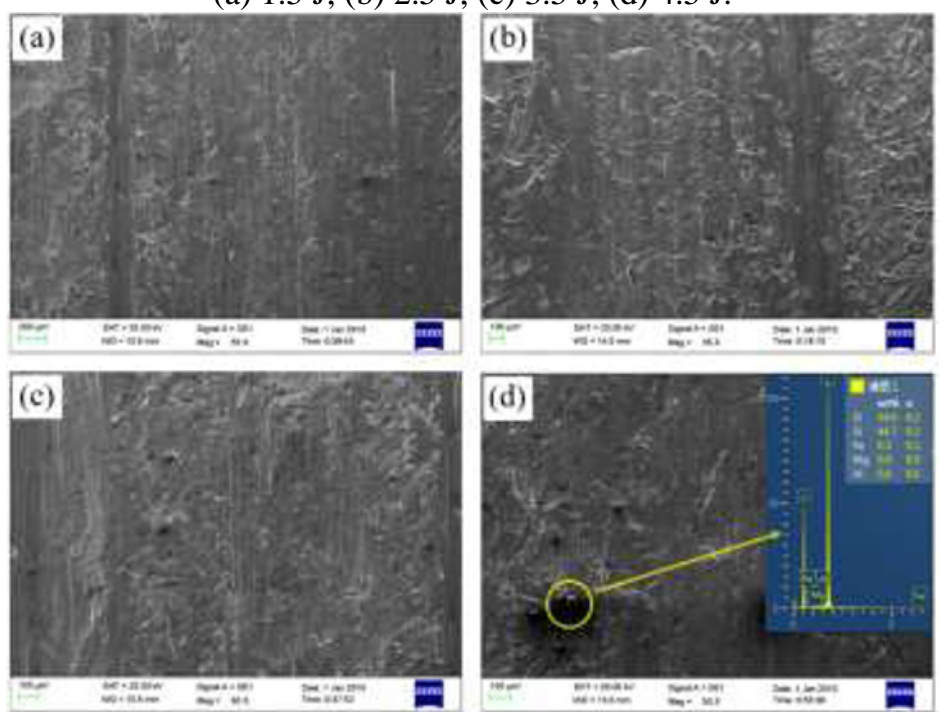

Figure 6. Worn surface of the counterpart ring under different impact energies:

(a) $1.5 \mathrm{~J}$; (b) $2.5 \mathrm{~J}$; (c) $3.5 \mathrm{~J}$; (d) $4.5 \mathrm{~J}$. 


\section{Conclusions}

In order to study the wear condition of the counterpart rings during the wear tests, the worn morphologies of the rings, which corresponding to the different impact energies were observed, and the obtained images are The impact abrasive wear behavior of HCWI produced by liquid die forging process were studied under the impact energies of $1.5 \mathrm{~J}, 2.5 \mathrm{~J}, 3.5 \mathrm{~J}$ and $4.5 \mathrm{~J}$ in this work. The main conclusions are drawn as follows:

(1) The microstructure of HCWI exhibits a typical dendritic structure, and the eutectic structure between dendrites are composed of carbide shaped fish-bone, stripy or massive, martensite and retained austenite. And the impact fracture characteristics of HCWI is river pattern, which formed by the confluence of cleavage steps.

(2) The cumulative volume loss of HCWI sample increases with the growth of impact energy, and for given impact energy, the volume loss increases with the increasing of wear time, which shown an approximately liner tendency.

(3) The wear characteristics of HCWI is mainly based on the shallow ploughing and accompanied by plastic deformation under low impact energy, when the impact energy increases to a medium value, the wear characteristics are mainly shown as wider and deeper ploughing and cutting, as well as some embedded abrasive. When the impact energy reach to a high value, however, the fatigue peeling and embedded abrasive become the most significant characteristics.

\section{Acknowledgments}

This work was supported by the Fundamental Research Funds for the Central Universities under Grant No. 2018YJS139

\section{References}

1. H.H. Ding, C.G. He, L. Ma, Wear 352, 1 (2016)

2. V. Ratia, I. Miettunen, V.T. Kuokkala, Wear 301, 94 (2013)

3. E.G. Moghaddam, N. Karimzadeh, N. Varahram, Mater. Sci. Eng. A 585, 422 (2013)

4. B. Narayanaswamy, P. Hodgson, H. Beladi, Wear 350, 155 (2016)

5. M. Lindroos, K. Valtonen, A. Kemppainen, Wear 322, 32 (2015)

6. V.G. Efremenko, K. Shimizu, T. Noguchi, Wear 305, 155 (2013)

7. T. Wang, M. Shozaki, M. Yamamoto, Mater. Des. 66, $498(2015)$

8. W. Wang, C. Zhang, P. Xu, Mater. Des. 73, 35 (2015)

9. M. Antonov, R. Veinthal, D.L. Yung, Wear 322, 971 (2015)

10. S. Wang, L. Song, Y. Qiao, Tribol. Lett. 50, 439 (2013)

11. Z. Zeng, L. Wang, L. Chen, Surf. Coat. Technol. 201, $2282(2006)$

12. M.S. Bingley, S. Schnee, Wear 258, 50 (2005)

13. P. Kulu, R. Veinthal, M. Saarna, Wear 263, 463 (2007)

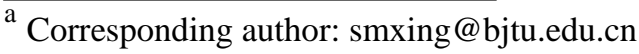

